\title{
EL $A R S$ DE RAMON LLULL Y SU DIFUSIÓN \\ EN ÉPOCA MODERNA: ENCICLOPEDIA, HERMETISMO, CÁBALA Y MNEMOTECNIA
}

\author{
César Chaparro Gómez \\ Universidad de Extremadura
}

\section{RESUMEN}

En este artículo se realiza un acercamiento elemental a la ingente y compleja obra de Ramon Llull (Raimundo Lulio), haciendo especial hincapié en el carácter enciclopédico de la misma, así como en su relación con el arte de la memoria y, en menor medida, con la Cábala y el hermetismo. Finalmente, a grandes rasgos se traza una panorámica de la influencia posterior de Lulio.

Palabras clave: Raimundo Lulio, enciclopedia, arte de la memoria, Cábala, hermetismo.

\section{RAMON LLULL'S ARS AND ITS SPREAD THROUGHOUT THE MODERN AGE: ENCYCLOPEDIA, HERMETISM, CABBALA AND MNEMOTECHNICS}

\section{Abstract}

In this article an elementary approach to Ramon Llull's enormous and complex work is made, with special emphasis on its encyclopaedic nature, as well as on its relationship with the art of memory and, to a lesser extent, with the Cabbala and hermetism. Finally, a broad outline of Llull's subsequent influence is presented.

KeYwORDs: Raimundus Lullus, encyclopaedia, art of memory, Cabbala, hermetism. 


\section{INTRODUCCIÓN}

Nuestros conocimientos sobre Ramon Llull (Raimundo Lulio) eran, hasta hace un tiempo relativamente reciente, más bien escasos ${ }^{1}$. El acercamiento a la persona y obra de Llull nos ha venido motivado por el conocimiento de uno de los muchos «afluentes» que este caudaloso río intelectual tuvo a lo largo y ancho de la cultura occidental. Me refiero concretamente a Diego Valadés, un misionero franciscano del siglo Xvi que vivió desde su niñez en Nueva España, autor de una obra monumental (Rhetorica Christiana, Perugia, 1579) en la que -razones había para ello- no se hace mención alguna a Llull, pero en cuyo desarticulado contenido los presupuestos lulianos, temáticos y formales, con especial atención al carácter enciclopédico y al arte de la memoria, aparecen por doquier inundando los largos y farragosos capítulos de un teórico y práctico «itinerario» o prontuario para los misioneros noveles ${ }^{2}$.

Y no ha de resultar extraña esta dependencia. Durante los últimos años del Medievo, Lulio, aparte del ejemplo vital dado por su comprometida actividad misionera, se convirtió para muchos cristianos, sobre todo para los miembros de las órdenes religiosas (franciscanos, preferentemente), en el agente restaurador de un cristianismo más apegado a los modelos evangélicos de vida, así como a la conversión de los infieles no por la fuerza, sino por el uso de la razón. De esa manera, el lulismo podía constituir un método idóneo, reflejado en su Ars, para lograr la unidad de la Cristiandad de forma pacífica, método que adoptaron en gran medida los humanistas cristianos, impulsores de las ideas de unitas y renouatio.

Raimundo Lulio (Mallorca, 1232/3-1316), autor prolífico y poliédrico, personaje difícilmente encasillable, es uno de los escasos pensadores de la península Ibérica que ha acaparado la atención de importantes figuras del pensamiento euro$\mathrm{peo}^{3}$. Lulio y el lulismo en su variopinta manifestación ha estado presente en la historia intelectual de Europa desde la Edad Media, pasando por los sueños de una

${ }^{1}$ El hecho de que nuestro conocimiento de la obra de Ramon Llull sea tan reciente y tangencial hace que esta contribución sea necesariamente un acercamiento general a sus propuestas, más producto de nuestros intereses concretos que del estudio concienzudo de sus complejos planteamientos. Los títulos de algunos de nuestros trabajos sobre Lulio indican bien a las claras esos intereses: «Enciclopedia y Retórica: De Raimundo Lulio a Diego Valadés». Fortunatae, vol. 19 (2008), pp. 9-25; «Enciclopedismo y mnemotecnia en Raimundo Lulio», en Estudios de Latín Medieval Hispánico, Firenze, SISMEL Edizioni del Galluzzo, 2011, pp. 219-224.

2 Sobre Diego Valadés ya hemos publicado una monografía, en la que se recogen nuestros estudios (más de treinta contribuciones) sobre su persona y obra: Fray Diego Valadés. Evangelizador franciscano en Nueva España. Badajoz, Centro Extremeño de Estudios y Cooperación con Iberoamérica, 2015.

${ }^{3}$ Las referencias, explícitas e implícitas, a las contribuciones del Dr. Rafael Ramis Barceló, uno de los mejores conocedores de la obra de Ramon Llull, son constantes a lo largo de estas páginas. Son especialmente interesantes las síntesis que hace del intelectual mallorquín y de su contextualización temporal y local, por ejemplo, en las líneas liminares que encabezan el número monográfico dedicado a Lulio en el Anuario Filosófico: R. Ramis Barceló, «Presentación». Anuario Filosófico, vol. 49, núm. 1 (2016), pp. 9-18; o el estudio preliminar que este mismo autor realiza a la traduc- 
ciencia universal en el Renacimiento, hasta las discusiones sobre el método científico en la primera modernidad. Es difícil encontrar una personalidad que haya suscitado reacciones y comentarios tan contradictorios, merecido tantos menosprecios y, al mismo tiempo, exaltaciones tan fervorosas ${ }^{4}$. La posición extrema de los dos bandos se debía, en un principio y en buena parte, a la identificación de nuestro personaje con la orden franciscana y su espiritualidad o forma de vivir la realidad del Evangelio de Cristo.

Y como ha sucedido con otros autores de indudable trascendencia, tanto en la Antigüedad como en la Edad Media, a partir de los años que siguieron a su muerte, se atribuyeron a la autoría de Lulio obras que nada tenían que ver con su pensamiento y que con frecuencia contenían doctrinas, si no contrarias, sí alejadas de lo escrito y enseñado por él. Por ello no es extraño que Lulio a lo largo de la historia haya sido desfigurado y falsificado: véase, si no, cómo las obras seudolulianas (como con anterioridad sucedió con Agustín de Hipona o Isidoro de Sevilla) pueblan las listas de las obras adjudicadas al beato mallorquín.

Antes de abordar, aunque sea en líneas muy generales dada la índole de esta contribución, el análisis de la compleja obra de Llull y su repercusión, y para no caer en su descontextualización (error cometido con mucha frecuencia en este caso), sino para insertarla en un tiempo y un lugar concretos, fruto a su vez de una larga tradición cultural -ya que algunas de las para muchos «novedades» de Lulio no son tales-, haremos unas previas y elementales reflexiones.

\section{CONSIDERACIONES PREVIAS}

La primera de las reflexiones está unida al muy acertado título del libro de Juan Ignacio Sáenz-Díez Ramón Llull. Un medieval de frontera (Madrid, Anaya \& M. Muchnik, 1995). De doble frontera podríamos añadir: en el ámbito geopolítico y en el epistemológico. Para entender el proyecto intelectual y misionero, especialmente este último, de Raimundo Lulio se ha de tener presente que fue hijo de colonos catalanes que se establecieron en Mallorca pocos años después de la conquista de la isla por Jaime I. Ramon Llull conoció de cerca a los infieles, pues judíos y musulmanes coexistían en Mallorca con los cristianos y el árabe era la lengua de uso de los venci-

ción de la obra luliana Ars de iure (hecha por los Dres. Ramis Serra y Ramis Barceló): Universidad Carlos III de Madrid, 2011, p. 11 y ss. En estos trabajos se encuentra bibliografía selecta al respecto.

${ }_{4}^{4}$ Por poner algunos ejemplos significativos, digamos que Bruno o Leibniz manifiestan su dependencia de Lulio. Sin embargo, otros autores, como Descartes, Bacon o Gassendi, lo critican: "Método engañoso salpicado de cierta ciencia», afirma Bacon; «el Arte de Lulio es una ciencia cabalística, impropia de hombres cuerdos y llena de figuras y tablas totalmente inútiles», apostilla Gassendi. O nuestro P. Feijoo, ya en el siglo XvinI, que tacha el método de Llull como "el más inútil y vano", "un caos o laberinto", comparable al cabalismo, a los buscadores de la piedra filosofal y a los cultivadores de la Crisopopeya (puede verse a este respecto nuestro trabajo «Feijoo y el Arte de la Memoria», en J. CAÑAS et alii, AUFKLÄRUNG. Estudios sobre la Ilustración española dedicados a Hans-Joachim Lope, Cáceres, Universidad de Extremadura, 2007, pp. 225-242). 
dos. El infiel era para algunos un ser abstracto, al que se tenía que combatir bélicamente y, de forma secundaria, intelectualmente. Llull se percató de que poco o nada podía lograrse así y que era necesaria otra aproximación: él no solo fue un hombre de contemplación, sino también, y principalmente, un hombre de acción y de misión.

En cierta medida, Ramon Llull fue un «retrasado cultural», como le han definido algunos autores, puesto que, en su juventud, seguía un agustinismo sui generis y desconocía las novedades del aristotelismo y las sutilezas de la logica noua. Él se formó de manera autodidacta en la frontera meridional de la Cristiandad, mediante un contacto con el "otro", la alteridad religiosa que quería convertir mediante argumentos racionales.

Llull no estudió, pues, en el corazón de la escolástica de su época. Los viajes y estancias en Montpellier, Roma, Génova y París le abrieron los ojos a nuevas realidades epistemológicas que no alteraron, en esencia, su visión profundamente periférica y mediterránea. En Mallorca se dejaba sentir el latir de todos los pueblos del Mare Nostrum occidental, un lugar transitado desde el que podía tener Llull una visión a vista de pájaro de lo que sucedía entre todos los territorios que bordeaban el mar, desde el estrecho de Gibraltar hasta Sicilia y Malta, bordeando las costas italianas, francesas y del levante de la península Ibérica. Raimundo Lulio viajó repetidas veces al norte de África y allí intentó su proyecto de conversión. Para él, la misión y el contacto con el infiel fueron elementos fundamentales en su vida.

En opinión de los magistri de la época, Llull no estaba solo en el margen, sino incluso fuera de la cultura y el saber de su época: era, ante todo, un laico iletrado en un universo intelectual dominado por el clero y la escolástica. Sin embargo, él -no olvidemos su experiencia mística en el Monte Rada- se sentía portador de una iluminación, de una revelación divina superior a toda aquella jeringonza latina, a la que siempre menospreció. Su obra, el Ars, un intrincado instrumento o sistema representado mediante colores, ruedas y triángulos, era la base para varias operaciones novedosas, entre las que sobresalían la presentación racional del cristianismo, la vía de la persuasión para los infieles y la base epistemológica para edificar todo el conocimiento.

Esto último nos permite hablar del sentido de la segunda frontera: la epistemológica. Al estar situado Llull fuera de las murallas del saber académico, pudo examinar con total libertad tanto las fuentes utilizadas como la división competencial de las Facultades del momento. Frente a la visión pragmática de los magistri de su tiempo, la impronta agustiniana de Lulio le impedía cualquier concesión a la tentación disgregadora y averroísta. Para él, la unidad del saber era una realidad primordial. No podían existir dobles verdades y, por lo tanto, tenía que existir una concordancia no solo entre filosofía y teología, sino también entre estas y las Artes liberales, la medicina y el derecho. Su Ars sería el instrumento para lograr un conjunto de principios ontológicos aplicados a todos los saberes. Raimundo Lulio debió de contemplar con asombro la división acomodaticia y competencial entre teólogos, canonistas, civilistas, médicos y filósofos. Cada disciplina tenía, en la segunda mitad del siglo XIII, sus propios principios, reglas y métodos. Y lo que es peor, cada una de ellas tenía su "verdad», que a menudo era incompatible con las "verdades» alcanzadas por el resto de las Facultades. 
Llull critica frontalmente la falta de unidad del saber, así como la dudosa idoneidad de las fuentes, elegidas por un mero criterio de autoridad y antigüedad. Así sucedía con la medicina galénica, las leyes justinianeas, los cánones compilados de Graciano y su amigo Raimundo de Peñafort, la filosofía neoplatónica y aristotélica, así como la teología basada en la obra de Pedro Lombardo, un centón sin coherencia interna. Frente a esta realidad, Lulio enarboló la bandera de la unidad del conocimiento y del método único. En realidad, él quiso redibujar las fronteras del saber, desdeñando las que encontró en las universidades de su tiempo. Evitó las divisiones «competenciales» y buscó, en definitiva, un método único que uniese internamente todos los saberes mediante el Ars como hilo conductor.

La segunda de las reflexiones tiene que ver con el desarrollo del corpus teórico y práctico del cristianismo en los siglos anteriores a Llull. Para el cristiano, la palabra de Dios y, por lo tanto, su voluntad para con la Humanidad se reflejan en dos escenarios distintos, ya que son dos los «libros esenciales» en los que estas se pueden «leer»: de una parte, el libro por excelencia, la Biblia, y, de otra, el «libro de la Naturaleza", es decir, la creación: Dios se refleja en sus criaturas. Ambos libros habían sido escritos por Dios. Para leer, entender y divulgar el primero de ellos, la Biblia, era preciso dominar las artes del lenguaje, que se hallaban sistematizadas en el triuium (gramática, retórica, dialéctica). Para hacer lo propio con el libro virtual de la creación -obra excelente en la que se reflejaba la perfección de su hacedor- había que acudir a las artes del número o quadriuium (aritmética, geometría, astronomía y música). Todo este conjunto -los dos libros y las siete disciplinas- constituía la enciclopedia cristiana; en términos de la teoría retórica, las disciplinas del triuium estarían mayormente referidas a la elocutio -más tangencialmente a la memoria y a la actio- mientras que las del quadriuium -a las que habría que añadir gran parte del contenido de la Biblia- entrarían en el ámbito de la inuentio.

Antes de que se llegue a los sucesivos ejemplos de enciclopedias del siglo XVII, una de las características principales del saber enciclopédico se concentra propiamente en el tema del lenguaje, interpretado como primaria clauis, indispensable llave de acceso metodológico al texto, a todo tipo de texto escrito y por tanto a toda la cultura desde los antiguos a los contemporáneos, visto en la prospectiva de una nueva y fecunda convergencia entre uerba y res. Las palabras corresponden a las cosas como el libro refleja la naturaleza y el mundo. Así pues, no existen diferencias entre los signos visibles de Dios puestos en la tierra y las palabras legibles de las Sagradas Escrituras o las que los santos Padres de la Antigüedad han puesto en los libros que las aclaran e interpretan. En este sentido, Llull tiene tras de sí, en la tradición occidental enciclopédica, el libro de las siete artes liberales de Marciano Capela, las Institutiones de Casiodoro, las Etymologiae de Isidoro de Sevilla, etc.

Dejando a un lado de nuestra reflexión la lectura y comprensión de la palabra de Dios, expresada a través de la Biblia, ¿̇ómo se presentaba o articulaba la organización de esa Naturaleza? Pasando por alto otras concepciones, nos fijaremos en la que arranca del pensamiento platónico, posteriormente asumida por el neoplatonismo y especialmente por Dionisio el Areopagita, san Agustín, Boecio, etc. Platón había postulado que había una jerarquía de espíritus en los cielos; Dionisio identificó a dichos espíritus con los diferentes seres angélicos mencionados en las Sagra- 
das Escrituras y los dispuso en una jerarquía de nueve órdenes, motores a su vez de las nueve esferas celestes (serafines, querubines, tronos, etc.). Por encima de la jerarquía de seres angélicos estaba Dios en el décimo cielo empíreo, y por debajo estaban las criaturas de la tierra: primero el hombre, luego los animales y las plantas y finalmente la auténtica hez del universo. Cada orden de criaturas estaba jerárquicamente ordenado en su interior. De ese modo el universo mostraba estar constituido por una cadena continua de criaturas que iba desde Dios en la periferia del universo hasta el inferior habitante del infierno. Por tanto, un esquema vertical, jerárquico - podríamos decir arbóreo-, a la hora de presentar el libro virtual de la Naturaleza, creada por Dios.

En este contexto y en el terreno práctico, con el fin de explicar el mundo o naturaleza, se puso en práctica como forma de expresión el empleo de lo que se conoce como stemmata o diagramas, que organizaban áreas del conocimiento humano articuladas en el universo creado por Dios. Así la diagramática se utilizó de forma creciente sobre todo a partir del siglo XII en la Europa medieval: se planteaba una exégesis del mundo enfocada desde la perspectiva de la lógica mental ${ }^{5}$. La geometría, además de ordenar el universo imponiendo un sistema a cada aspecto de la existencia, encontró su manifestación idónea en el diagrama o stemma. De ahí que el diagrama medieval tuviera como objetivo establecer una visión analítica del mundo, en virtud de la cual la materia de estudio (inuentio) se dividía en partes que establecían categorías dentro de sus componentes. Se añadió a estos diagramas la ornamentación, que tenía una función decorativa en algunos casos, simbólica en otros y en muchas mnemotécnicas. Gran parte de las reglas de la mnemotecnia se dejó ver claramente en la construcción de diagramas visuales, cuyas partes constituyentes, que se podían considerar loci memorísticos, se recorrían mentalmente encaminando al alma al recogimiento dentro de un proceso meditativo.

Y dentro del rango figurativo del diagrama, las formas más comunes fueron los árboles, las escaleras y las ruedas. Estas últimas ciertamente se habían usado en la Antigüedad como fórmulas de poesía visual, pero en este caso la elección de la forma respondió tanto a una exégesis tipológica como a una distinctio escolástica de la mentalidad medieval. La exégesis tipológica e histórica adoptó desde árboles esquemáticos de vicios y virtudes hasta explicaciones históricas correspondientes a los árboles genealógico-religiosos de Joaquín de Fiore. Por otra parte, las rotae (ruedas) no eran solo vehículos que enunciaban verdades, sino que también ofrecían al predicador y al lector la posibilidad de encontrarlas a través de un ejercicio personal, al establecer relaciones y proposiciones lógicas a medida que se iba descifrando la forma.

5 En este ámbito, nos ha resultado muy interesante el libro de L. Bolzoni, La estancia de la memoria. Modelos literarios e iconográficos en la época de la imprenta. Madrid, Cátedra, 2007, en especial el capítulo II, «Árboles del saber y máquinas retóricas» (pp. 53-123). Asimismo, puede consultarse nuestro trabajo "Retórica, memoria y diagrama en la Rhetorica Christiana de Diego Valadés». Humanistica Lovaniensia, vol. 57 (2008), pp. 185-208. 


\section{LA OBRA DE RAIMUNDO LULIO: UN PROYECTO MISIONERO}

La obra de Raimundo Lulio no se entiende sin hacer mención del objetivo que se marcó en su vida: servir a Cristo. Después de su conversión, entendió que debía cumplir un triple deber: intentar convertir a los infieles, escribir el mejor libro del mundo que serviría de método para tal conversión e intentar convencer a las autoridades religiosas y civiles de la necesidad de fundar monasterios, no universidades, para la formación de misioneros.

El origen, por lo tanto, del proyecto de Llull hay que buscarlo, no en la asunción de unos presupuestos o contenidos académicos, la mayor parte de ellos racionales y científicos, sino en una experiencia iluminativa, la que él tuvo en el año 1272 en el Monte Randa, montaña mallorquina, en la que -según su propia confesión- vio los atributos de Dios (a los que denominará dignitates), su bondad, grandeza, eternidad, etc., atributos que penetraban la creación entera, percatándose de esa manera de que se podría construir un Arte que se fundara en esos atributos, que serían universalmente válidos por basarse en la realidad. Poco tiempo después produjo la primera versión de su Ars, del que hizo múltiples versiones, la última de ellas el Ars Magna (1305-1308). Por lo tanto, la obra de Raimundo Lulio ha de ser juzgada como una propuesta misional, de índole global y unitaria. Este claro propósito le obligó a multiplicar la forma y el contenido de los escritos, de manera que con ellos pudiera aproximarse tanto a los profesores universitarios como a los dignatarios eclesiásticos y civiles, a las personas letradas o, más directamente, a los infieles. Interpretar su proyecto desde otro prisma, más concreto y particular o exclusivista (filosófico, científico, etc.), sería borrar su intencionalidad primera y principal.

Hablar de originalidad del pensamiento de Llull es examinar los dos rasgos fundamentales del planteamiento de su labor misionera: uno es la idea de no basar sus argumentos en citas de autoridades, con lo que contravenía la praxis medieval, y el otro la de no obrar por la vía negativa de querer refutar las ideas de sus adversarios, sino la positiva de intentar demostrar la fe cristiana. El primer rasgo lo empujaba a encontrar bases de argumentación aceptables para musulmanes y judíos, pero que al mismo tiempo le servían de premisas de sus pruebas. El segundo lo animaba a romper la barrera que se había erigido entre fe y razón, entre Revelación y Aristóteles, entre la teología y la filosofía. Y estos dos rasgos juntos le obligaban a moverse dentro de un circuito cerrado en el que premisas, fe y razón obrasen concordes ${ }^{6}$.

Así, dando por sentado que el gran objetivo del Arte luliano era de carácter misionero, como sistema o andamiaje de persuasión dialéctico, su autor creía que si con él podía persuadir a los judíos y a los musulmanes, estos se convertirían al cristianismo, puesto que el Ars se basaba en principios y concepciones generales acep-

${ }^{6}$ Estas ideas están tomadas de la excelente monografía (la excelencia radica en la magnífica síntesis que se hace de la vida y del proyecto intelectual y misionero de Lulio) de L. BAdía \& A. Bonner, Ramón Llull: Vida, pensamiento y obra literaria. Barcelona, Sirmio Quaderns Crema S.A., 1993, pp. 73-80. 
tables y comunes a las tres grandes religiones (la existencia de un solo Dios, bueno, omnipotente y eterno, fuente de toda justicia), así como en la estructura elemental del mundo natural aceptado por la ciencia de su tiempo, es decir, en la cosmovisión de su época.

Las concepciones religiosas comunes eran los Nombres de Dios: Dios es bueno, grande, eterno, sabio, etc. Tales nombres, que, por una parte, pertenecen a la tradición cristiana (san Agustín menciona muchos de ellos y en el De diuinis nominibus del Seudo Dionisio se les registra extensamente), son fundamentales también en el judaísmo y particularmente en el tipo de mística judía que se conoce con el nombre de Cábala. Bajo la influencia de la Cábala, cuyas doctrinas se estaban propagando por España, los judíos españoles contemporáneos de Llull meditaban con particular intensidad en los Nombres de Dios. Así, las diez Sefirot de la Cábala son realmente los Nombres Divinos entendidos como principios creativos. Una forma de meditación que por entonces estaba particularmente desarrollada en España consistía en meditar sobre las letras del alefato hebreo, combinándolas y volviendo a combinarlas para formar los Nombres de Dios. El mahometanismo, por su parte, particularmente en su forma mística sufita, concedía también gran importancia a la meditación de los Nombres de Dios. Esta práctica la desarrolló particularmente el místico sufita Mohidin, cuya influencia sobre Llull ha sido frecuentemente sugerida.

\section{EL $A R S$ DE RAIMUNDO LULIO}

Es precisamente el monoteísmo de las tres religiones, al que hay que unir la herencia común del pensamiento griego, el que permite a Llull construir la base más sólida y característica de su sistema. En efecto, el Ars de Ramón Llull se basa en el uso de la combinatoria de notaciones alfabéticas, las cuales designan conceptos universales y, por lo tanto, son aplicables a todas las diferentes ramas del saber, desde la teología, la lógica y la jurisprudencia hasta las ciencias como la astronomía y la geometría. Para que esta lógica combinatoria se llevara a cabo de manera práctica, Llull ideó una serie de figuras geométricas. Estas consistían en círculos concéntricos giratorios, triángulos y cuadrados. Dichas figuras diagramáticas son estructuras combinatorias diseñadas con el fin de que, mediante una serie de notaciones alfabéticas, el espectador/lector practique la meditación visual sobre la organización del universo 7 . Con la meditación sobre dichas figuras, Lulio pretendía también que el lector ejercitara las tres potencias del alma: memoria, entendimiento y voluntad. Mediante la práctica de estas, se llegaría al amor y conocimiento de Dios: «La primera -dice Llull-, recuerda lo que la segunda entiende y la tercera quiere; la

7 Tanto en nuestras contribuciones referidas a la obra de Diego Valadés como en la elaboración de este trabajo hemos echado mano de la rigurosa y útil monografía de L. BÁEz RuBí, Mnemosine novohispánica. Retórica e imágenes en el siglo XVI. México, UNAM (Instituto de investigaciones estéticas), 2005, p. 61 y ss. 


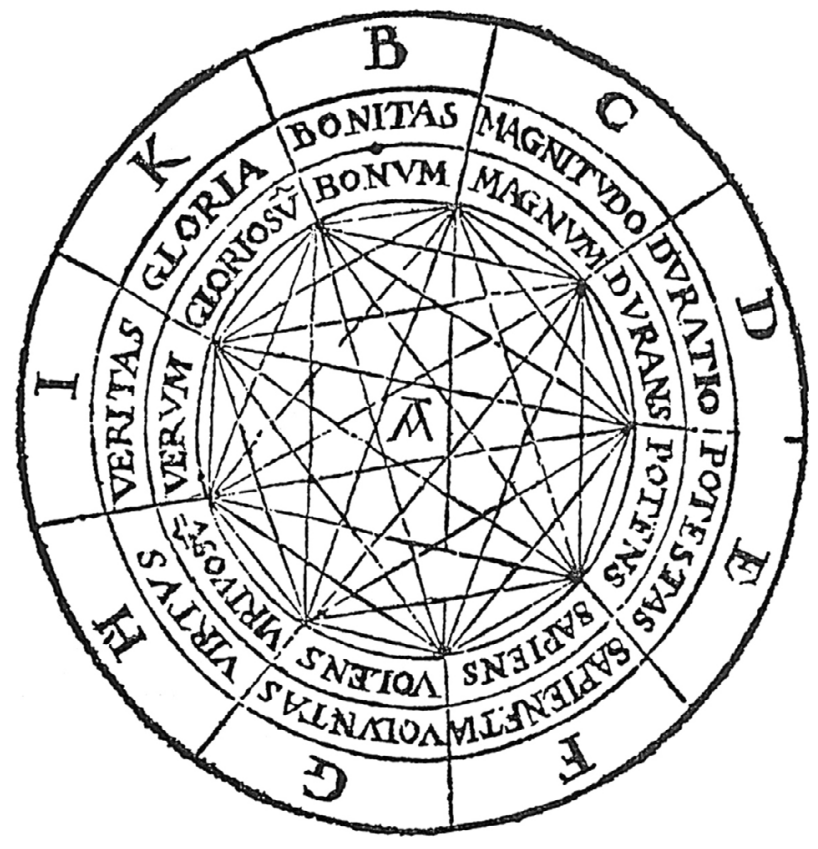

Figura 1. Combinatoria de Dios y sus dignidades.

segunda entiende lo que la primera recuerda y la tercera quiere; la tercera quiere lo que la primera recuerda y la segunda entiende».

Es importante hacer notar que, en este caso, la memoria se basa enteramente en «reales filosóficos» o verdades filosóficas. Estas vienen a ser las dignidades (dignitates Dei), también llamadas conceptos universales, que actúan como principios absolutos, universales y regidores del mundo y que están relacionadas con los distintos nombres o atributos de Dios. Se ha vertido mucha tinta sobre el significado del término dignitates y las fuentes teológicas y filosóficas de donde Llull pudo haberlo tomado. Todo ello nos remite y pudo provenir, como ya adelantamos, de la concepción del hadrah árabe, las sefirot hebraicas y las ideas divinas del neoplatonismo cristianizado.

Las dignidades divinas o atributos de Dios se concretaron y redujeron en las últimas versiones del Ars a nueve: bondad, grandeza, eternidad, poder, sabiduría, voluntad, virtud, verdad, gloria (fig. 1).

Sobre estos atributos, Llull hacía tres afirmaciones básicas, que resultarían irrefutables para gente que, como los judíos y los musulmanes, creía en un Dios único que existía en el grado máximo de perfección. La primera tenía que ver con el papel de las dignidades dentro de la unidad divina. Llull afirmaba que eran reales, que eran concordantes entre sí sin ningún tipo de contrariedad y que se convertían mutuamente en una simplicísima esencia divina, y, por tanto, lo que en el mundo aparece como pluralidad es, en Dios, unidad. La expresión «se convertían» 
quiere decir que la bondad de Dios es grande, su grandeza es buena, su bondad es eterna, etc. Así, lo que en el mundo creado aparece como una mezcla de cosas distintas en Dios opera con los componentes mutuamente convertibles de su unidad, y esto hasta constituir la definición misma de Dios.

La segunda afirmación se concreta en lo siguiente: las dignidades tienen sus actos propios sustanciales, intrínsecos y eternos, «sin los cuales [...] estarían ociosas y esto ab aeterno». Esto se entremezcla con la doctrina neoplatónica, bien conocida entre musulmanes y judíos, según la cual el bonum est diffusiuum sui. Y esto, que sea difusivo de sí mismo, es propio del bien, ya que Dios Padre genera de su bondad al Hijo bueno, y de ambos procede el Espíritu Santo bueno.

Si la segunda afirmación tiene que ver con la actividad necesaria ad intra de Dios, la tercera tiene que ver con su actividad contingente ad extra, que según Llull había tenido dos resultados fundamentales: la creación misma y, en consecuencia, la relación entre Creador y creado. En lo que atañe al primero de estos resultados, era importante poder probar la creación contra la tesis de la eternidad del mundo, mantenida por Aristóteles y Averroes. En lo que atañe al segundo, era el camino que tomaba Llull para probar «la Encarnación, en la que se produce la unión del Creador y la criatura en la sola persona de Cristo", construyendo de esa manera un puente entre lo infinito y lo finito ${ }^{8}$.

Conviene subrayar que esta naturaleza activa existía en todos los niveles del ser, desde las dignidades divinas hasta los últimos escalones del mundo creado, y cada cosa era activa ad intra, como el fuego que quema, y ad extra, como el fuego que calienta el agua en una olla. También hay que subrayar que esta ontología, en la cual ser y acción eran convertibles, era una innovación notable de Llull, que lo diferenciaba sensiblemente de la mayoría de sus contemporáneos escolásticos, para los cuales el ser era más bien convertible en la inmovilidad o quietud que con la acción, y que llamó poderosamente la atención de sus seguidores inmediatos.

En lo que atañe a la cosmovisión, Lulio parte del concepto típicamente medieval de la escala de las criaturas. Esta teoría comprendía tres ideas esenciales: primeramente, la idea del orden: que el mundo representaba un sistema ordenado; en segundo lugar, la idea de la jerarquía del ser o de los seres; y en tercer lugar, una visión de la creación constituida por una serie de planos superpuestos, que reflejan todos el mismo original o ejemplar divino, y que conservan por tanto una relación analógica entre ellos.

La idea del orden ya estaba presente en la Biblia: Omnia in mensura et numero et pondere disposuisti («Todo lo dispusiste con medida, número y peso»Sap. 11, 21). Las divisiones jerárquicas del ser comenzaban con la separación entre el mundo increado del Creador y el mundo que Él había creado, que a la vez se dividía en mundo espiritual (ángeles, almas humanas) y mundo material (minerales, plantas y animales). A veces Llull explicaba estos tres mundos con una analogía gramatical, donde los relacionaba con los tres grados de un adjetivo: superlativo, comparativo y positivo.

${ }^{8}$ L. Badía \& A. Bonner, Ramón Llull..., p. 77 y ss. 
Pero más importante era la relación de nexo proporcionada por el segundo de estos (el mundo espiritual) entre los otros dos. De aquí provenía el papel primordial del hombre en la economía del cosmos; por su alma pertenecía al mundo espiritual, y a través de él participaba en el mundo divino. Además, según Lulio (recogiendo una tradición que proviene de san Agustín), el alma humana (o «racional», como él dice), se divide en tres facultades o "potencias»: la voluntad, el entendimiento y la memoria, reflejo claro de la trinidad del ejemplar divino.

Al mismo tiempo, el hombre por su cuerpo pertenecía al mundo material, y participaba (o mejor dicho, contenía) los cuatro escalones del mundo material inferior. Así que compartía con minerales, plantas y animales la cualidad del ser «elementado", compuesto por los cuatro elementos, aire, fuego, agua y tierra; con plantas y animales compartía la cualidad "vegetativa» (la capacidad de absorber alimentos y crecer); y con los animales compartía las dos cualidades, la «sensitiva» (la de utilizar los cinco sentidos) y la «imaginativa» (la de formarse una imagen mental de una cosa no presente en los sentidos). A esta jerarquía del ser, ordenada y analógica, herencia común de la cosmovisión cristiana medieval, Llull añadió otra red de relaciones, la de los correlativos, que la interconectó aún más.

Hemos hecho mención de los cuatro elementos. Es importante observar cómo trata Lulio este asunto, fundamental, como bien sabemos, para la medicina medieval, así como para los campos que hoy clasificaríamos como química y física. Fue representado por una figura, de la que conviene destacar: 1) para Llull cada elemento tenía su cualidad propia (el fuego, por ejemplo, era caliente por sí mismo) y apropiada (el fuego era seco por la sequedad que la tierra le prestaba), mecanismo que provocaba una circulación de cualidades en el sentido contrario de las agujas del reloj; 2) lo que a Llull interesaba no eran tanto los elementos en sí como su actividad, representada por las cualidades, es decir, su interrelación activa (fig. 2).

Otra jerarquía igualmente común a todo el mundo medieval explica la colocación física de cada componente. Esta dividía el mundo en dos esferas: la esfera celestial, compuesta por el cielo empíreo, el firmamento astral y los cursos de los siete planetas, donde todo era constante e inmutable, y la esfera sublunar, compuesta por los cuatro elementos, donde todo era mutable e inconstante, por el hecho de estar sometido a la generación y a la corrupción, es decir, a la composición y la descomposición. Esta jerarquía se organizaba como las capas de una cebolla, con la tierra y sus cuatro elementos en el centro. Los siete planetas incluían la luna y el sol (no así la tierra), el firmamento incluía los doce signos del zodíaco, y en el cielo empíreo vivían «los ángeles y las almas de los hombres santos delante de Jesucristo y de nuestra Señora». Finalmente, las capas interiores recibían las influencias de las exteriores, sobre todo astrológicas, de los planetas y de los signos del zodíaco, influencias transmitidas por las cuatro cualidades elementales (calor, frío, humedad, sequedad) que cada planeta tenía en diferentes grados.

Digamos algo de forma muy elemental y somera sobre la presentación y la finalidad de su Ars. Lulio afirma que el Arte, como cualquier otra ciencia, tiene cuatro causas, que son en resumidas cuentas las causas aristotélicas: autor, materia, forma y fin. El autor es Dios, «el autor inmediato». La materia son las figuras y los términos (letras) del Arte mismo. La forma está en el descenso de un universal a 


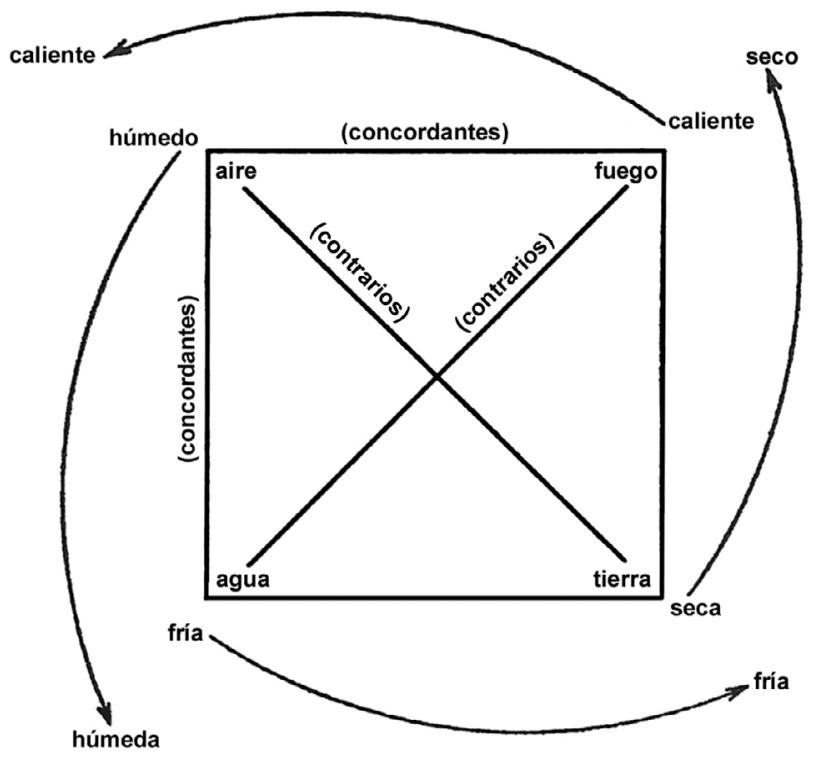

Figura 2. Los cuatro elementos.

los particulares y la finalidad es la necesaria afirmación de la verdad o la negación de la falsedad.

Sobre la materia (figuras y alfabeto), hay que decir que las letras no representan variables, como en la lógica aristotélica o en el álgebra poscartesiana, sino que funcionan como constantes que representan los términos básicos del Arte; las figuras, por su parte, no tienen ningún valor simbólico o mágico, sino que funcionan como ayudas visuales y mnemotécnicas, con el fin de mostrarnos cómo están agrupados e interrelacionados los términos. Letras y figuras formalizan las bases del Arte y hacen posible su mecanismo combinatorio. En cuanto a la forma del Arte (descenso de lo universal a lo particular o relación entre lo particular y lo universal), Lulio la entiende como la del ejemplo que participa de lo ejemplar y no como que lo particular es una mera parte de lo universal, cosa que sucedía en el mundo aristotélico.

Sobre la finalidad del Arte, Llull afirma que es la de «encontrar» (inuenire) o «demostrar» la verdad, asunto en el que Llull insiste repetidamente. Sobre este tema hallamos títulos igualmente significativos como el Ars compendiosa inveniendi ueritatem, el Ars inuentiva ueritatis y el Ars demonstratiua. Ello se relaciona con los orígenes y los fines dialécticos de su Arte, así como con la idea básica de abordar la apologética desde una base positiva lo más amplia posible, siguiendo el presupuesto inicial de que hay que probar la fe cristiana en lugar de refutar la del adversario.

De los múltiples métodos que utiliza Llull para demostrar esta verdad solo citaremos dos. Uno se basa en la idea, de antigua tradición neoplatónica, de equiparar el bien al ser, y de tomar el mal como privación o no-ser. Sobre este fundamento construye Llull un tipo de lógica binaria que guarda cierto parecido con las 
tablas de verdad de la lógica moderna: en el lado positivo encontramos una concordancia entre bondad, perfección, mayor nobleza, mérito y ser y, en el negativo, una concordancia entre maldad, imperfección o defecto, menor nobleza, culpa y no-ser. Puesto que la culminación de la escala del ser es Dios, está claro que la primera serie concuerda con afirmación y verdad mientras que la segunda concuerda con negación y falsedad. El segundo método, presente en toda la obra luliana, es la prueba por los grados de perfección. En la escala del conocimiento y del ser Lulio ve tres escalones: el positivo (bueno, grande, etc.) del mundo sensible; el comparativo (mejor, mayor, etc.) del entendimiento; y el superlativo (óptimo, máximo, etc.) de la esfera divina. Haciendo subir a nuestro entendimiento por esta escala, se llega a un conocimiento superior, espiritual; y formulando pruebas de la necesaria superioridad del último escalón, pueden demostrarse verdades del mundo divino.

En resumen, entre las primeras y las últimas versiones del Ars, Lulio ha recorrido un largo camino, para lograr que su dispositivo sea capaz de tratar no solamente problemas de teología y metafísica, sino también de derecho, medicina, astronomía, etc. El Ars se convierte así en un instrumento apto para afrontar la enciclopedia entera del saber, recogiendo las sugerencias de las muchísimas enciclopedias medievales existentes y anticipando la «utopía» enciclopédica de la cultura renacentista y barroca.

\section{EL "ÁRBOL DE LA CIENCIA»: ENCICLOPEDIA Y MEMORIA}

La combinatoria de los principios lulianos se manifestó también en la expresión literaria, especialmente dentro de una obra que Lulio presentó como una enciclopedia del conocimiento, el "Árbol de la ciencia» (Arbor scientiae) (fig. 3).

Esta enciclopedia lulista se vertebra alrededor de la idea fundamental de la unidad del conocimiento humano que a su vez refleja la unidad del universo. Cada ciencia se representa como un árbol. Son dieciséis árboles, de los que los primeros catorce siguen el sentido de la escala del ser y por lo mismo son una organización jerárquica del universo creado: árbol elemental, árbol vegetal, árbol sensual, etc., hasta el árbol «cristianal» (de Jesucristo) y el árbol divinal. A su vez, cada uno de los árboles está dividido en siete partes: raíces, tronco, brazos, ramas, hojas, flores y frutos. Los principios-raíces eran la base del conocimiento enciclopédico, puesto que se aplicaban en forma combinatoria a todas las ciencias y a todos los seres del universo; eran dieciocho, nueve referidos a las dignidades divinas y los restantes a los principios (diferencia, concordancia, etc.). Aunque el sistema pueda parecer esquemático, los árboles lulianos expresan una clara sistematización del conocimiento que organiza y simplifica el estudio de las diversas disciplinas tratadas.

El hecho de que Lulio haya optado por escoger un formato arbóreo para exponer su doctrina se debe a que funcionaba como una herramienta lógica para facilitar la predicación. De esa manera, así como los ejemplos de la enciclopedia se usaban para entender contenidos científicos del universo, también servían para moralizar por medio de la predicación de virtudes y vicios. 


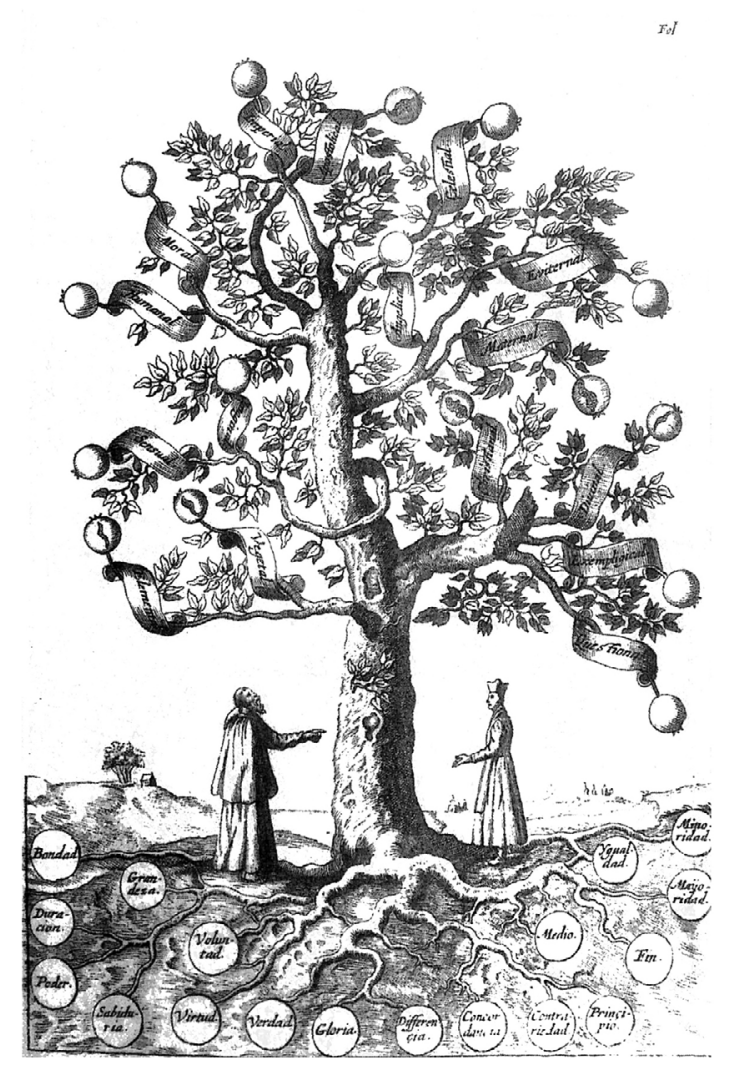

Figura 3. Árbol de la ciencia (trad. Alonso Cepeda, Bruselas, 1665).

El método enciclopédico-arbóreo de Lulio viene a ser, pues, un corpus orgánico y unificado del conocimiento a la vez que una clasificación sistemática de los elementos de la realidad. En este caso, el papel que desempeña la memoria era el de guardar el conocimiento natural asociado con la doctrina moral en la mente. Esto se ajustaba al sentido neoplatónico de la adquisición del conocimiento verdadero, mediante las imágenes de las cosas creadas, que, en este caso, actuaban como símbolos de la filosofía natural: el lulismo mnemónico funcionaba basándose en un mecanismo que representaba procesos lógicos. Estos fundaban relaciones combinatorias entre constantes o principios universales, a fin de retener la estructura del universo entero con la ayuda de sistemas claramente clasificatorios?.

${ }^{9}$ En este ámbito resultan muy interesantes las ya clásicas reflexiones de F. YATES, en su famosa obra El Arte de la memoria. Madrid, Ed. Siruela, 2005, en especial el capítulo viII, «El lulismo como arte de la memoria» (pp. 197-220). 
De hecho, este modelo adquirió mayor protagonismo cuando Lulio se preocupó por satisfacer la necesidad de un verdadero sistema de oratoria sagrada. Para lograrlo se valió del sermón como medio de predicación, y lo estructuró alrededor de los principios del Arte para difundir sus ideas ${ }^{10}$. Así el predicador, utilizando el arte luliano, podía dar cuenta del proceso creativo de Dios y su manifestación en el mundo físico por vía de su actividad para dar existencia a todos los seres. La forma de transmitir la lógica combinatoria luliana, asociada estrechamente con la retórica, implicaba un método de predicación por el que el oyente conocería a Dios de manera racional. Como consecuencia tendería a abrazar las virtudes y a odiar los vicios, a practicar los sacramentos, cumplir los diez mandamientos, emprender obras de misericordia, etc. Todo con el fin de lograr su conversión.

En resumen, el método lulista del libre «ascenso y descenso" del intelecto, ejercido bajo el prisma de una movilidad combinatoria de principios, permite el acercamiento meditativo a la comprensión de la acción divina y su relación con el ser humano. Esto se lleva a cabo mediante la memoria lógico-científica, según la cual se recuerda la conformación del universo y de los seres a través del uso de las escalas y figuras. El papel de la memoria en Ramon Llull, en conjunción con las otras dos potencias del alma, cumplía con la siguiente función: cuando el entendimiento pregunta por qué el hombre obra con justicia, se dice que ascendiendo a lo racional y al fin para lo que es creado, que es para que recuerde, entienda y ame a Dios de manera justa y prudente, por razón de su bondad, grandeza, etc. En Llull el memorar consiste en que, una vez halladas las especies a lo largo del ascenso del entendimiento, se las encomienda a la memoria; y mediante esta conservación o «impresión» de las especies se puede entender la organización del universo, con el fin de contemplar la magnitud creativa de Dios, y así finalmente amarlo. La práctica lulista con objetivos mnemotécnicos se propuso, pues, crear una conciencia plena sobre la omnipotencia de la figura divina y de su proceso creador: «La memoria le es dada al alma para que recuerde al soberano Bien, del cual todos los bienes provienen».

Resulta primordial, pues, destacar la idea medular que presenta la enciclopedia luliana, concretada en el «ascenso y descenso del intelecto por los grados de las causas, desde lo más elevado a lo más ínfimo y desde lo más ínfimo a lo más elevado». Como se ha dicho, la imagen de una enciclopedia arborizada implicaba en el ánimo de los seguidores del Ars de Lulio la firme creencia en la unidad del saber. Esta idea expresaba su intención de concretar y relacionar todo el conocimiento, mediante el uso iconográfico de "la cadena de ciencias o del árbol de las ciencias", que se correspondían perfectamente con la estructura armoniosa y jerárquica del cosmos. La unidad del saber lleva implícita la unidad del universo, así como la dis-

${ }^{10}$ De esa manera, Lulio no siguió el modelo tradicional de oratoria, conforme al cual el dogma cristiano se manifestaba a través del sermón per auctoritates; en cambio, su propuesta de sermón era más libre, en el sentido de que los principios del Arte servían como instrumentos con que se hacía uso de las razones necesarias para demostrar la verdad cristiana (per intelligere). 
tribución y organización del conocimiento implicaba una distribución y organización del universo.

Es evidente que todas estas construcciones figurativas y mnemónicas son válidas -las de Lulio y, posteriormente, las de algunos renacentistas-, porque se tiene la convicción de que en la mente limitada del hombre, concebido como una chispa de la divinidad, se puede contener el ilimitado saber-contenido del universo. Para ello se necesitaba una estructura mnemónica que permitiera abarcar algo que supera los límites de su capacidad habitual. Solo si el microcosmos se cree igual al macrocosmos puede contener el uno al otro y hacerse intercambiables, desde los niveles celestiales a los más bajos, desde las ciencias físicas y biológicas a las mágicas y teológicas.

\section{EL LULISMO DESPUÉS DE LULIO}

Después de la muerte de Raimundo Lulio, su pensamiento se difundió notablemente y generó interesantes polémicas a lo largo de cuatro siglos. La prohibición, en algunos momentos, de las obras de Llull y el ataque de los antilulistas no pudo frenar el auge que iba adquiriendo su pensamiento ${ }^{11}$. El lulismo renació con fuerza a finales del siglo Xv en la península Ibérica, guiado por el magisterio de Pedro Daguí (Ianua artis magistri Raymundi Lulli, 1482). Varios humanistas mantuvieron una estrecha relación con él, caso de Nicholas de Pax o el cardenal Jiménez de Cisneros ${ }^{12}$. Estos personajes, que formaron un círculo hispánico lulista, trabaron vínculos intelectuales con pensadores franceses que impulsaron el renacimiento del lulismo parisiense (Jacques Lefèvre d'Étaples y Charles Bouvelles, principalmente). Últimamente se viene diciendo que sin el lulismo no se puede entender bien el pensamiento renacentista. Sin embargo, el lulismo no representa una tradición, sino que se divide en varios riachuelos a los que hay que sumar las corrientes seudolulianas de la alquimia y el cabalismo. El primer hilo que se retomó fue el de la metafísica luliana, por obra de uno de los pensadores más importantes del siglo xv, Nicolás de Cusa. La característica más propia e innovadora de esta metafísica fue el concepto de una realidad dinámica o activa, estructurada mediante el sistema de los correla-

${ }^{11}$ Como botón de muestra de la amplia polémica -en tiempo y lugar- que suscitó la obra de Lulio y de la persecución que sufrieron sus seguidores, valgan algunos trabajos del mencionado R. Ramis Barceló, «El proceso de la Inquisición contra la lectura del Arte de Ramón Llull en la Universidad de Zaragoza (1610)». Hispania Sacra, vol. LXvi, núm. extra I (2014), pp. 131-160; «La Inquisición de México y la calificación del Árbol de la ciencia de Ramón Llull (1665-1669)». Estudios de Historia novohispana, vol. 48 (2013), pp. 189-214; «Pasquines de lulistas y antilulistas en 1750 (Biblioteca Pública de Palma, ms. 1146)». BSAL, vol. 65 (2009), pp. 285-300.

12 De hecho, el cardenal Jiménez de Cisneros fundó una cátedra de filosofía y teología lulianas en la Universidad de Alcalá y, algunos años después, el rey Felipe II nombró al lulista Pedro de Guevara tutor de dos de las infantas. 
tivos. Este concepto manejado como principio ontológico tuvo una influencia fundamental en el pensamiento del Cusano ${ }^{13}$.

Igualmente interesaba el aspecto del sistema luliano que permitía que la fe y la razón obrasen conjuntamente, con el fin de demostrar los artículos de la fe y, sobre todo, los referidos a la Trinidad y la Encarnación: Lulio defendía una teología natural, frente a una teología de la Revelación. Sin embargo, esta teología natural fue una causa más de conflicto en la historia del lulismo: para el estamento clerical representaba una amenaza a su autoridad como intérprete de la Revelación.

Como corolario a esta teología natural, la renovación por parte de Raimundo Lulio de la vieja doctrina agustiniana de la unidad del saber dentro de un Ars aeterna -como una base general para todos los campos del saber humano y una ciencia de las ciencias-, que a su vez hacía posible un enciclopedismo orgánico, llamó poderosamente la atención de pensadores de los siglos XVI y XVII. La idea de un enciclopedismo total y orgánico quedó flotando en el aire durante esos siglos y las numerosas reformulaciones de esta idea hasta el siglo XVIII tienen siempre una deuda implícita con la obra de nuestro pensador.

Otra deuda que tenían los pensadores del Renacimiento y del Barroco para con Llull hace referencia a su Ars combinatoria, con las posibilidades que parecía ofrecer para mecanizar los fundamentos de nuestro conocimiento, para reconstruir un campo del saber humano o su totalidad sobre la base de un pequeño núcleo de conceptos y para tener, al menos en teoría, una manera casi infalible para distinguir la verdad de la falsedad. La idea de poder lograr todo esto mediante cálculos semimatemáticos es un sueño intelectual que nos parece eterno y que todavía continúa vivo en las investigaciones modernas sobre la inteligencia artificial y los «sistemas inteligentes». Lo cierto es que tal innovación fascinó a dos de las figuras más características de los siglos XVI y xviI: Giordano Bruno y Leibniz. Este último, bajo la influencia directa del Arte de Llull, escribió su primera obra (Dissertatio de arte combinatoria). Y también en Leibniz confluyó esta corriente de la combinatoria con la otra ya citada de la posibilidad de una ciencia general, para dar lugar a sus investigaciones encaminadas al hallazgo de una mathesis uniuersalis.

Asimismo, durante el Renacimiento, a la Cábala cristianizada se la identificó con el lulismo no solo por funcionar ambos sistemas conforme a un principio combinatorio de letras (Lulio combina B-K), sino también por presentar como elementos generales y fundamentales de combinación los atributos divinos ${ }^{14}$. Esta identificación, apuntada por una autoridad indiscutible del Renacimiento, Pico della Mirandola, se fortaleció y se difundió con el tratado seudoluliano De auditu cabbalistico (Venecia, 1516). La herencia de esta nueva identificación influyó en todos los cabalistas cristianos posteriores: estos tomaron

${ }^{13}$ L. Badía \& A. Bonner, Ramón Llull..., p. 215 y ss.

${ }_{14}$ Resultan esclarecedoras las páginas de U. Eco, en su obra La búsqueda de la lengua perfecta (edición electrónica, http://www.philosophia.cl/, Escuela de Filosofía Universidad ARCIS), en especial el capítulo seis, "Cabalismo y lulismo en la cultura moderna" (pp. 85-102). 
el Ars combinandi de Llull como base de sus operaciones cabalistas y le asociaron el pensamiento mágico-astrológico, como hizo Jean Thritème. Igualmente, otros autores le incorporaron la mnemotecnia clásica con su complejo sistema de loci e imágenes agentes, como Francesco di Giorgio o Giulio Camillo. Mediante estos sistemas, todos estos pensadores, de una u otra manera, buscaban desarrollar una clave universal que les diera acceso al conocimiento de la armonía universal para, con ella, lograr la restauración del mundo y del ser humano ${ }^{15}$.

Estas corrientes, junto con la de la aplicabilidad universal del Arte, confluyeron igualmente en otros ámbitos que interesaron a los pensadores de los siglos XVI y xviı, que hallaron la manera de utilizar el Arte luliano como base de un arte del discurso o de un arte de la memoria, o que pretendían seguir el camino más estrictamente luliano, consistente en usarlo como una especie de «lógica nueva». Ahí están las obras de Bernardo de Lavinheta ${ }^{16}$, Cornelius Agrippa, Johann H. Alsted y, después de Leibniz, la de una de las figuras más curiosas de la historia intelectual europea, el jesuita Athanasius Kircher, quien publicó en 1669 su Ars magna sciendi como reforma del Arte de Raimundo Lulio.

Otra fusión que se produjo, aparte de la mencionada entre la obra luliana y la Cábala, fue la del Ars de Lulio y la alquimia. Desde comienzos del siglo XIV aparecieron bajo el nombre de Raimundo Lulio numerosos y variados tratados sobre alquimia. Al parecer Llull nunca empleó el Arte en relación con materias alquímicas, pero sí lo empleó en relación con la materia próxima de la medicina astral. Fue justamente el dinamismo del concepto luliano del ser lo que los alquimistas tuvieron por muy útil: si el ser no era el resultado de un acto único, y por tanto cerrado para siempre, sino un proceso que seguía produciéndose a través de las semejanzas de sus dignidades y de su actividad, habría que concluir que el ser no era susceptible de la inmutabilidad con la que los alquimistas topaban normalmente.

Así pues, vemos al Lulio renacentista siendo considerado como una especie de mago, versado en la Cábala y en las ciencias herméticas que se cultivaban en la tradición ocultista. En una obra atribuida falsamente a Lulio (In rhetoricam

${ }^{15}$ Conviene en este sentido aclarar, antes de terminar estas líneas, que lo que diferencia el pensamiento cabalístico del de Llull, en la medida y modo en que se pueda hablar propiamente de este en el intelectual mallorquín, es que en la Cábala la combinatoria de las letras engendra realidad, más que reflejarla; la realidad que el místico cabalista debe descubrir no le es conocida y solo podrá revelarse a través del silabeo de las letras que permutan rápidamente. En cambio, la combinatoria luliana es un instrumento retórico mediante el cual se pretende demostrar lo ya conocido, lo que la estructura del bosque de los distintos árboles ha fijado ya de una vez para siempre, y que ninguna combinatoria podrá jamás subvertir.

16 Especialmente importante resulta la figura de B. de Lavinheta, punto de unión entre Raimundo Lulio y el franciscano Diego Valadés, misionero mencionado en el inicio de estas líneas. Lavinheta se interesó por el aspecto enciclopédico del pensamiento lulista, creando el modelo renacentista de la enciclopedia que influirá posteriormente en autores posteriores (Valerio de Valeriis, entre otros). 
Isagoge, París, $1515^{17}$ ) encontramos el misterioso lenguaje del ocultismo y de la magia, cuando se habla de «una nueva luz que emerge de la oscuridad y que insta a un silencio pitagórico».

Tiempo después, con la Ilustración, Lulio desapareció casi por completo del panorama europeo, ya que un sistema tan apriorístico y teocéntricamente sintetizador como el suyo no tenía cabida ya en un mundo regido por una ciencia fundamentalmente empírica, laica y especializada. Podría decirse que el enciclopedismo francés fue la última reformulación de una empresa que se había iniciado con nuestro personaje, pero que las bases de este nuevo universalismo eran ya tan distintas que los mismos Diderot y D’Alembert hubieran tenido por ridícula cualquier comparación.

En nuestros días, ha habido notables progresos en el conocimiento de la obra del beato mallorquín y de su consiguiente estimación. Autores como Frances Yates, en su libro Lulio y Bruno, o Umberto Eco, en la monografía La búsqueda de la lengua perfecta, ponen de manifiesto el protagonismo de Ramon Llull y de su obra a través de la historia cultural de Occidente. La primera ha dicho: «El lulismo no es ningún asunto lateral y sin importancia en la civilización occidental. Su influencia a lo largo de cinco siglos fue incalculablemente grande». Por su parte, este es el interesante resumen que nos hace Eco de la figura y de la obra del pensador mallorquín:

Resulta pues de gran trascendencia que se redescubra el pensamiento de un hombre que había hecho de su predicación y de su reflexión teológica un medio para tender un puente intelectual y religioso entre el Occidente europeo y Oriente y que consideraba que la verdadera autoridad no se basaba en una unidad rígida, sino en una tensión entre diversos centros, de modo que tanto la ley de Moisés, como la revelación de Cristo y la predicación de Mahoma pueden conducir a un resultado unitario. El lulismo es acogido como un estímulo místico y filosófico, y como una alternativa fantástica y poética a la enciclopedia del aristotelismo escolástico, pero también como una inspiración política. Además, la obra de un escritor que se atrevió a escribir en vulgar concuerda con un humanismo que precisamente está celebrando la dignidad de las lenguas vulgares y su pluralidad, pero que al mismo tiempo se plantea el problema de cómo se puede elaborar un discurso supranacional de la razón, de la fe y de la filosofía, que sea capaz de introducir en el cuerpo de la enciclopedia escolástica los fermentos, en vías de desarrollo, de nuevas doctrinas exóticas, expresadas en lenguas todavía profundamente desconocidas ${ }^{18}$.

Vuelvo al inicio de estas líneas, al poner de manifiesto que mi acercamiento a Ramon Llull vino motivado por el estudio de la obra del misionero franciscano

${ }^{17}$ Esta obra es claramente un manual para predicadores que destaca los principios del arte luliano empleados como material de predicación, y organizados de acuerdo a un sistema de mnemotecnia lógica. Por otra parte, la tonalidad «ocultista» y de magia del tratado se observa ya en las palabras introductorias de In rhetoricam: «Dios, con su obra y gracia, comienza el arte de la retórica, la cual es nombrada alquimia de las palabras. De las tinieblas emerge la misma luz. Pues Él mismo dispuso las tinieblas como su refugio, el que apreció en el monte circundado por la calígine y la niebla».

${ }^{18}$ U. Eco, La búsqueda de..., p. 53. 


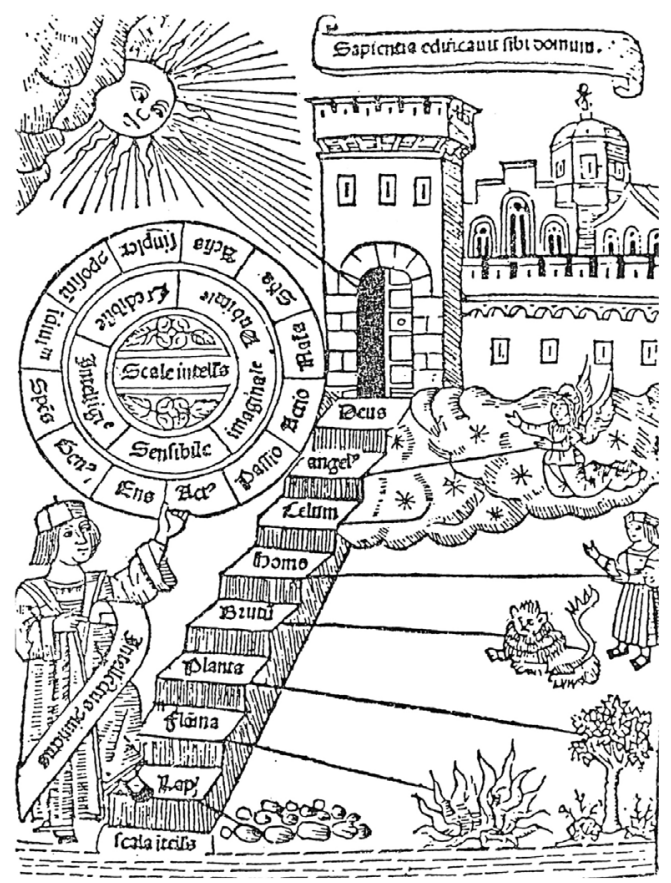

Figura 4. La escala del Ascenso y del Descenso (Valencia, 1512).

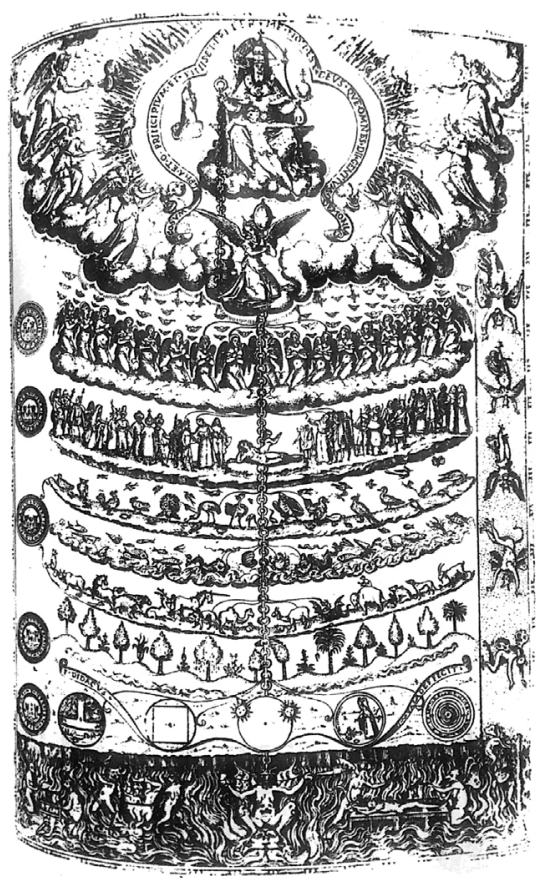

Figura 5. La cadena del ser (Rhet. Chris., Diego Valadés).

Diego Valadés. En su Rhetorica Christiana, sin hacer mención alguna a Llull, aparecen una y otra vez, como inuentio o corpus de su predicación a los indígenas infieles, los conceptos lulianos de las dignidades de Dios, de los principios relativos y de los sujetos, etc. Pero lo que más llama la atención es que, al ser la obra de este evangelizador la primera retórica ilustrada, muchos de los grabados, realizados por el propio Valadés para adoctrinar a unos pueblos que carecían de alfabeto, son copia tres siglos después de algunas de las figuras utilizadas por Lulio. Ahí están, para probarlo, los grabados del «Ascenso y descenso en la escala del ser» de Ramon Llull (fig. 4) y la "Cadena del ser» del fraile franciscano Valadés (fig. 5), por una parte, o el «Árbol de la ciencia-árbol apostolical» de Llull y el «Árbol de la jerarquía eclesiástica» de Diego Valadés, por otra. 


\section{BIBLIOGRAFÍA}

Badía, Lola \& Antoni Bonner, Ramón Llull: Vida, pensamiento y obra literaria. Barcelona, Sirmio Quaderns Crema S.A., 1993.

BÁez Rubí, Linda, Mnemosine novohispánica. Retórica e imágenes en el siglo XVI. México, UNAM (Instituto de investigaciones estéticas), 2005.

Bolzoni, Lina, La estancia de la memoria. Modelos literarios e iconográficos en la época de la imprenta. Madrid, Cátedra, 2007.

Chaparro, César, «Enciclopedia y Retórica: De Raimundo Lulio a Diego Valadés». Fortunatae, vol. 19 (2008), pp. 9-25.

Chaparro, César, "Enciclopedismo y mnemotecnia en Raimundo Lulio», en Estudios de Latín Medieval Hispánico, Florencia, SISMEL Edizioni del Galluzzo, 2011, pp. 219-224.

Chaparro, César, «Feijoo y el Arte de la Memoria», en J. Cañas et alii, AUFKLÄRUNG. Estudios sobre la Ilustración española dedicados a Hans-Joachim Lope, Cáceres, Universidad de Extremadura, 2007, pp. 225-242.

Chaparro, César, «Retórica, memoria y diagrama en la Rhetorica Christiana de Diego Valadés». Humanistica Lovaniensia, vol. 57 (2008), pp. 185-208.

Chaparro, César, Fray Diego Valadés. Evangelizador franciscano en Nueva España. Badajoz, Centro Extremeño de Estudios y Cooperación con Iberoamérica, 2015.

Eco, Umberto, La búsqueda de la lengua perfecta. Ed. electrónica, http://www.philosophia.cl/. Escuela de Filosofía Universidad ARCIS [https://www.ddooss.org/libros/umberto_eco.pdf].

Ramis Barceló, Rafael, «El proceso de la Inquisición contra la lectura del Arte de Ramón Llull en la Universidad de Zaragoza (1610)». Hispania Sacra, vol. Lxvi, núm. extra I (2014), pp. 131-160.

Ramis Barceló, Rafael, «La Inquisición de México y la calificación del Árbol de la ciencia de Ramón Llull (1665-1669)». Estudios de Historia novohispana, vol. 48 (2013), pp. 189-214.

Ramis Barceló, Rafael, «Pasquines de lulistas y antilulistas en 1750 (Biblioteca Pública de Palma, ms. 1146)». BSAL, vol. 65 (2009), pp. 285-300.

Ramis Barceló, Rafael, «Presentación». Anuario Filosófico, vol. 49, núm. 1 (2016), pp. 9-18.

Ramis Barceló, Rafael, Estudio preliminar al Ars de iure, trads. Ramis Serra y Ramis Barceló, Universidad Carlos III de Madrid, 2011.

YATEs, Frances, El Arte de la memoria. Madrid, Ed. Siruela, 2005. 
